\title{
NO-Dependent Endothelial Dysfunction in Type II Diabetes Is Aggravated by Dyslipidemia and Hypertension, but Can Be Restored by Angiotensin-Converting Enzyme Inhibition and Weight Loss
}

\author{
Ines Nevelsteen $^{\mathrm{a}} \quad$ An Van den Bergh $^{\mathrm{a}}$ Gerry Van der Mieren ${ }^{\mathrm{a}}$ \\ Annelies Vanderper $^{\mathrm{a}}$ Kanigula Mubagwa ${ }^{\mathrm{a}}$ Hidde Bult $^{\mathrm{b}}$ Paul Herijgers $^{\mathrm{a}}$ \\ a Department of Cardiovascular Sciences, Research Unit of Experimental Cardiac Surgery, KU Leuven, Leuven, and \\ ${ }^{\mathrm{b}}$ Department of Pharmacology, Universiteit Antwerpen, Antwerp, Belgium
}

\section{Key Words}

Angiotensin-converting enzyme inhibition - Diabetes mellitus type II - Endothelial dysfunction · Metabolic syndrome $\cdot$ Weight loss

\begin{abstract}
Aims: Insulin resistance, dyslipidemia and hypertension are independent mediators of endothelial dysfunction. It is incompletely defined whether dyslipidemia and hypertension in addition to diabetes mellitus type II (DMII), as seen in the metabolic syndrome (MS), worsen diabetes-induced endothelial dysfunction. Furthermore, it is unclear whether treatment influences endothelial dysfunction similarly in MS and DMII. Therefore, we studied vascular reactivity and the effect of in vivo treatment with angiotensin-converting enzyme inhibition (ACE-I) or hypocaloric diet in LDL receptor- and leptin-deficient (ob/ob), double knockout mice (DKO), featuring MS and in ob/ob mice with DMII. Methods and Results: Vascular reactivity was studied in isolated aortic ring segments. Maximum vasorelaxant response to acetylcholine
\end{abstract}

(Ach) was more depressed in DKO than in ob/ob mice, whereas response to bradykinin (BK) was equally attenuated in both genotypes ( $52 \pm 3$ and $23 \pm 9 \%$ reversal of preconstriction induced by $10^{-7} \mathrm{M}$ phenylephrine in DKO vs. $76 \pm 3$ and $23 \pm 8 \%$ reversal of preconstriction in ob/ob mice, respectively). ACE-I and hypocaloric diet improved AChinduced vasorelaxation significantly $(89 \pm 2$ and $59 \pm 2 \%$ reversal of preconstriction in DKO vs. $80 \pm 3$ and $84 \pm 4 \%$ in ob/ ob mice, respectively), but not the response to BK. Conclusion: These results indicate a differential impact of DMII and MS on endothelial function. ACE-I and hypocaloric diet improved ACh-, but not BK-induced vasorelaxation in these mouse models of DMII and MS.

(C) 2013 S. Karger AG, Basel

\section{Introduction}

Diabetes mellitus type II (DMII) is associated with an increased risk of cardiovascular morbidity and mortality due to both diabetic cardiomyopathy and angiopathy. Di-

\begin{tabular}{ll}
\hline KARGER & $\begin{array}{l}\text { C } 2013 \text { S. Karger AG, Basel } \\
1018-1172 / 13 / 0506-0486 \$ 38.00 / 0 \quad \text { Karger }\end{array}$ \\
$\begin{array}{l}\text { E-Mail karger@karger.com } \\
\text { www.karger.com/jvr }\end{array}$ & $\begin{array}{l}\text { This is an Open Access article licensed under the terms of the } \\
\text { Creative Commons Attribution-NonCommercial 3.0 Un- } \\
\text { ported license (CC BY-NC) (www.karger.com/OA-license), } \\
\text { applicable to the online version of the article only. Distribu- } \\
\text { tion permitted for non-commercial purposes only. }\end{array}$
\end{tabular}

Prof. Dr. Paul Herijgers

Experimental Cardiac Surgery, KU Leuven

Herestraat 49

BE-3000 Leuven (Belgium)

E-Mail paul.herijgers@med.kuleuven.be 
abetic angiopathy is characterized by abnormalities in vascular wall morphology and altered vascular reactivity. Emphasis has been laid on endothelial function in DMII in clinical and experimental studies [1-5]. Endothelial dysfunction refers to loss of the modulatory function of the endothelium with an imbalance between vasorelaxation and vasoconstriction, resulting in a propensity towards vasoconstriction. Impaired endothelium-dependent relaxation is well documented in DMII, which is mainly caused by reduced nitric oxide (NO) bioavailability. Additional contributing factors might include: a decreased production of other relaxing factors, an increased production of vasoconstricting agents or a reduced sensitivity of vascular smooth muscle to relaxing factors $[3,6,7]$.

Specific changes due to DMII are often confounded by other cardiovascular risk factors, such as hypertension and dyslipidemia. This is the case in the metabolic syndrome (MS), which is defined by the co-occurrence of at least three of the following features: abdominal obesity, dyslipidemia, hypertension, insulin resistance \pm glucose intolerance and proinflammatory and prothrombotic status [8]. Although it is well known that MS implies a significantly increased risk of developing vascular complications, it remains unclear whether dyslipidemia and hypertension combined with DMII worsen diabetes-induced alterations in vascular function. We have extensively characterized cardiac dysfunction in MS using a homozygous LDL receptor (LDLR)-/- and ob/ob-/-, double knockout mouse model (DKO) [9]. This model exhibits glucose intolerance, insulin resistance, hypertension and atherogenic dyslipidemia. No studies are available on vascular reactivity in this model and no study has compared vascular reactivity between DMII and MS to determine the possible differential impact of both pathologies on vascular reactivity.

Endothelial dysfunction is an important mediator of vascular disease progression [1]. Consequently, prevention and management of endothelial dysfunction is indispensable in reducing cardiovascular complications in patients with DMII and MS. Angiotensin-converting enzyme inhibition (ACE-I) and hypocaloric diet, in addition to hypoglycemic drugs, are currently the golden standard in the treatment of DMII and MS. ACE-I efficiently reduces cardiovascular complications, especially in DMII, because of an improvement in endothelial function, a reduction in cardiovascular remodeling, and its anti-atherosclerotic and anti-oxidative effects [10-12]. Although ACE-I reduces markers of oxidative stress in patients with MS [13], it is incompletely defined whether ACE-I influences vascular dysfunction similarly in MS and DMII.

Vasorelaxation and the Metabolic Syndrome
Weight loss ameliorates endothelial function [14, 15], but most studies on food restriction in obese patients with DMII are associated with lifestyle modifications and exercise training. Increased physical activity has proven to restore coronary artery and aortic endothelial dysfunction in DMII mice [16, 17]. Therefore, it is not clearly defined to what extent hypocaloric diet alone can contribute to an improvement in endothelial function because exercise training is often a confounding factor.

The aim of our study was to compare vascular reactivity and endothelial function between our mouse model of MS and ob/ob mice, a well-known model of DMII. The objective was to assess whether dyslipidemia and hypertension worsen impaired endothelial dysfunction in DMII mice. In order to assess the effect of isolated dyslipidemia, we also included LDLR-/- mice, which are normotensive, have high plasma lipid levels, but are not diabetic. A second aim was to evaluate the effect of in vivo treatment with ACE-I or with food restriction-induced weight loss on impaired vascular function in both mouse models. Data were compared to determine if ACE- I and hypocaloric diet influences vascular dysfunction similarly in MS and DMII.

\section{Methods}

Animals

Experiments were conducted in homozygous LDLR-/- and leptin-deficient (ob/ob) DKO of either gender at 24 weeks. ob/ob mice were used as model of DMII with C57BL/6J (wild type, WT) as reference data. LDLR-/- mice were included to assess the effect of isolated dyslipidemia. Mice were backcrossed for at least 10 generations into the C57BL/6J background and exhibit $98.4 \%$ C57BL/6J background. Heterozygous ob/+ and C57BL/6J mice were purchased from the Jackson Laboratory (Bar Harbor, Me., USA). Homozygous LDLR-/-, ob/ob and DKO mice were generated as described previously [18]. All mice were fed standard chow, containing $9 \%$ fat (Ssniff, Soest, Germany) with free access to water. The investigation conforms to the Guide for the Care and Use of Laboratory Animals published by the US National Institutes of Health (NIH Publication No. 85-23, revised 1996) and was approved by the institutional review board.

\section{Metabolic Analysis}

Blood was taken by tail bleeding into EDTA tubes after $24 \mathrm{~h}$ fasting. Blood glucose levels were measured with a glucometer (Menarini Diagnostics, Zaventem, Belgium). Plasma was obtained by centrifugation. Triglycerides, total cholesterol, HDL and LDL levels were determined with a diagnostic reagent kit (Roche, Vilvoorde, Belgium).

\section{Food Restriction}

All mice were fed standard chow containing 9\% fat (Ssniff) with free access to water. Food intake of DKO mice and LDLR-/mice was 5.7 and $2.5 \mathrm{~g} /$ day, respectively [19]. Food intake of diet- 
restricted mice (DKO and ob/ob) was reduced to the daily level of LDLR-/- food intake ( $2.5 \mathrm{~g} /$ day) for 12 weeks between 12 and 24 weeks of age.

\section{Angiotensin-Converting Enzyme Inhibition}

ACE-I was achieved using captopril (10 mg/kg i.p.) [20], which was daily injected during 12 weeks (from 12 weeks till 24 weeks of age) in ob/ob and DKO mice.

\section{Isolated Organ Bath Protocol}

Rings of $5 \mathrm{~mm}$ were taken from the thoracic aorta and placed in cold Krebs' solution containing (in $\mathrm{mM}$ ): $118.3 \mathrm{NaCl}, 4.7 \mathrm{KCl}$, $2.5 \mathrm{CaCl}_{2}, 1.2 \mathrm{MgSO}_{4}, 25 \mathrm{NaHCO}_{3}, 0.026 \mathrm{Na}_{2} \mathrm{Ca}$ EDTA, 5.5 glucose and $1.2 \mathrm{KH}_{2} \mathrm{PO}_{4}$. In one segment, the endothelium was preserved. In the other one, the endothelium was mechanically destroyed by gently rubbing the inside of the aortic ring with a stainless tube with rough surface. The rings were mounted on a force transducer (HSE force transducer F30 type 372; Harvard Apparatus, Holliston, Mass., USA) in an organ bath, filled with aerated $\left(95 \% \mathrm{O}_{2}\right.$ and $\left.5 \% \mathrm{CO}_{2}\right)$ Krebs' solution at $37^{\circ} \mathrm{C}$ and $\mathrm{pH}$ 7.45. Tissues were allowed to equilibrate for $30 \mathrm{~min}$, before being subjected to an increasing passive tension until optimal resting tension of $800 \mathrm{mg} / \mathrm{mm}$ (equals $7.8 \mathrm{mN} / \mathrm{mm}$ ) was reached after $30 \mathrm{~min}$. This optimal preload was based on preliminary experiments, during which active force development in response to $40 \mathrm{mM} \mathrm{KCl}$ was measured at various applied passive tensions (200-1,600 $\mathrm{mg} / \mathrm{mm})$. Tissues were equilibrated for another 30 min under optimal preload. Bath buffer was refreshed every $20 \mathrm{~min}$.

Vascular Reactivity of Thoracic Aorta Ring Segments in vitro

The integrity of the endothelial layer was tested by examining the response to acetylcholine ( $\mathrm{ACh}, 10^{-6} \mathrm{M}$ ) administered during preconstriction with phenylephrine $\left(\mathrm{Phe}, 10^{-7} \mathrm{M}\right)$. To determine vasomotor responses, increasing concentrations (from $10^{-9}$ to $10^{-5} \mathrm{M}$ ) of ACh, bradykinin (BK), sodium nitroprusside (SNP), Phe and angiotensin II (ATII) were used to generate a concentration-response curve. ACh, BK and SNP were administered on endothelium-preserved vessels precontracted with $10^{-7} \mathrm{M}$ Phe. Phe was selected as vasoconstrictor because vasomotor responses (expressed as percent relaxation) to endogenous and exogenous NO in aortic ring segments of $\mathrm{C} 57 \mathrm{BL} / 6 \mathrm{~J}$ mice, which were constricted with increasing concentrations of Phe, are identical, irrespective of the Phe contraction level obtained [21].

To assess intrinsic vascular smooth muscle cell (VSMC) properties, Phe was used on endothelium-denuded ring segments. At the end of the measurements, all tissues were challenged with $100 \mathrm{mM} \mathrm{KCl}$. This response was used to normalize contractile responses from other agonists.

\section{Data Management and Statistical Analysis}

All data are expressed per millimeter length of the ring segment. Results are presented as means \pm SEM. Data for vasorelaxation by $\mathrm{ACh}, \mathrm{BK}$ and SNP are expressed as percent relaxation compared to the initial preconstriction with $10^{-7} \mathrm{M}$ Phe with correction for the basal vessel tonus. Data for vasoconstriction by Phe and ATII are expressed as percent contraction, compared to the maximum response to $100 \mathrm{mM} \mathrm{KCl}$. n' denotes number of ring segments. ' $\mathrm{N}$ ' denotes number of animals. Concentration-response curves were fitted with a nonlinear regression model [with equa- tion: effect $=$ maximum effect $/\left(1+10^{\left.\left(\log \mathrm{EC}_{50}-\log \text { conc }\right) \text { Hillslope }\right)}\right]$, using GraphPad Prism (San Diego, USA). Statistica (Statistica 7.1; StatSoft, Tulsa, USA) was used to analyze metabolic and phenotypic parameters. Differences between groups were analyzed for statistical significance by one-way ANOVA, followed by a Tukey HSD post hoc test. A difference with $\mathrm{p}<0.05$ was considered significant. When aortic ring segments from male and female mice were separately analyzed, no difference could be obtained. Therefore, results from mice of either gender were combined.

\section{Results}

Phenotypic and Metabolic Features of WT, LDLR-/-, ob/ob and DKO at 24 Weeks

Phenotypic and Metabolic Features of MS in

Untreated DKO

At 24 weeks, DKO and ob/ob body weight (BW) was significantly higher, compared to WT and LDLR-/mice of the same age (table 1). Similarly, heart weight (HW) was higher in DKO and ob/ob, but the relative increase in $\mathrm{HW}$ was less marked than that of $\mathrm{BW}$, resulting in a significantly lower $\mathrm{HW} / \mathrm{BW}$ ratio. Blood glucose levels were increased in DKO and ob/ob, whereas dyslipidemia (high levels of total cholesterol, triglycerides and LDL) were present in LDLR-/- and DKO and less in ob/ob.

\section{Significant Weight Loss after in vivo Hypocaloric}

Diet

Twelve weeks of food restriction resulted in $41 \%$ lower BW in DKO and $47 \%$ in ob/ob (table 2). HW was also significantly lower in DKO and ob/ob after diet versus untreated groups. HW/BW ratio was significantly increased in ob/ob after hypocaloric diet compared to untreated ob/ob. A similar but less marked diet-induced effect on the HW/BW ratio was observed in DKO. Hyperglycemia was moderately reduced with diet in ob/ob and DKO. The atherogenic serum lipid profile was persistent in DKO after food restriction.

\section{Significantly Lower HW in DKO after in vivo Treatment with ACE-I}

Twelve weeks of ACE-I resulted in a significantly lower HW in DKO, but unchanged BW, leading to a small decrease in the $\mathrm{HW} / \mathrm{BW}$ ratio I (table 2). A similar, but more moderate decrease in $\mathrm{HW}$ without change in $\mathrm{BW}$ was obtained with ACE-I in ob/ob mice. Fasting glycemia was no longer increased in ob/ob after ACE-I whereas the hyperglycemic and atherogenic status of DKO remained present after treatment with ACE-I. 
Table 1. Phenotypic and metabolic characteristics of WT, LDLR-/-, ob/ob and DKO at 24 weeks

\begin{tabular}{|c|c|c|c|c|}
\hline & WT & LDLR-/- & $\mathrm{ob} / \mathrm{ob}$ & $\mathrm{DKO}$ \\
\hline BW, g & $27.1 \pm 0.9^{b, c}$ & $26.7 \pm 1.3^{\mathrm{b}, \mathrm{c}}$ & $64.5 \pm 1.0^{*, \mathrm{a}}$ & $60.7 \pm 1.9^{*, \mathrm{a}}$ \\
\hline $\mathrm{HW}, \mathrm{mg}$ & $164.4 \pm 9.6^{\mathrm{b}}$ & $153.6 \pm 7.8^{b, c}$ & $197.6 \pm 9.2^{*, \mathrm{a}}$ & $183.8 \pm 11.1^{\mathrm{a}}$ \\
\hline $\mathrm{HW} / \mathrm{BW}, \mathrm{mg} / \mathrm{g}$ & $6.3 \pm 0.5^{b, c}$ & $5.9 \pm 0.4^{\mathrm{b}, \mathrm{c}}$ & $3.1 \pm 0.2^{*, \mathrm{a}}$ & $3.0 \pm 0.1^{*, \mathrm{a}}$ \\
\hline Glycemia, mg/dl & $70.8 \pm 5^{\mathrm{b}, \mathrm{c}}$ & $69.4 \pm 7^{\mathrm{b}, \mathrm{c}}$ & $159.5 \pm 10.6^{*, \mathrm{a}}$ & $163.6 \pm 31.7^{*, \mathrm{a}}$ \\
\hline Total cholesterol, mg/dl & $76 \pm 4^{\mathrm{a}, \mathrm{c}}$ & $252 \pm 17^{*, b, c}$ & $136 \pm 10^{\mathrm{a}, \mathrm{c}}$ & $616 \pm 75^{*, a, b}$ \\
\hline Triglycerides, mg/dl & $60 \pm 4^{\mathrm{a}, \mathrm{c}}$ & $108 \pm 16^{b, c}$ & $67 \pm 3^{c}$ & $226 \pm 29^{*}$, a, b \\
\hline $\mathrm{HDL}, \mathrm{mg} / \mathrm{dl}$ & $65 \pm 5^{\mathrm{a}, \mathrm{b}, \mathrm{c}}$ & $132 \pm 11^{*, b, c}$ & $95 \pm 6^{*, a, c}$ & $186 \pm 15^{*, a, b}$ \\
\hline $\mathrm{LDL}, \mathrm{mg} / \mathrm{dl}$ & $1 \pm 0^{\mathrm{a}, \mathrm{c}}$ & $99 \pm 16^{*, c}$ & $27 \pm 5^{\mathrm{c}}$ & $385 \pm 63^{*, a, b}$ \\
\hline
\end{tabular}

Phenotypic and metabolic parameters in WT $(\mathrm{N}=12)$, LDLR-/- $(\mathrm{N}=10)$, untreated ob/ob $(\mathrm{N}=11)$ and $\mathrm{DKO}(\mathrm{N}=10){ }^{*} \mathrm{p}<0.05$ vs. WT, ${ }^{a} \mathrm{p}<0.05$ vs. LDLR-/-, ${ }^{\mathrm{b}} \mathrm{p}<0.05$ vs. ob/ob and ${ }^{\mathrm{c}} \mathrm{p}<0.05$ vs. DKO.

Table 2. The effect of 12 weeks of in vivo treatment with a hypocaloric diet or ACE-I in ob/ob and DKO at 24 weeks

\begin{tabular}{|c|c|c|c|c|c|c|c|}
\hline & WT & \multicolumn{3}{|l|}{$\mathrm{ob} / \mathrm{ob}$} & \multicolumn{3}{|l|}{ DKO } \\
\hline $\mathrm{HW}, \mathrm{mg}$ & $164.4 \pm 9.6^{\mathrm{a}}$ & $197.6 \pm 9.2^{*}$ & $136.3 \pm 2.8^{*, \mathrm{a}}$ & $178.7 \pm 4.0$ & $183.8 \pm 11.1$ & $132.7 \pm 2.9^{*}, \mathrm{~b}$ & $160.9 \pm 4.2^{\mathrm{b}}$ \\
\hline $\mathrm{HW} / \mathrm{BW}$ ratio, $\mathrm{mg} / \mathrm{g}$ & $6.3 \pm 0.5^{\mathrm{a}, \mathrm{b}}$ & $3.1 \pm 0.2^{*}$ & $4.3 \pm 0.3^{*, \mathrm{a}}$ & $2.7 \pm 0.1^{*}$ & $3.0 \pm 0.1^{*}$ & $3.9 \pm 0.2^{*}$ & $2.6 \pm 0.1^{*}$ \\
\hline Glycemia, mg/dl & $70.8 \pm 5^{\mathrm{a}, \mathrm{b}}$ & $159.5 \pm 10.6^{*}$ & $140 \pm 11.7^{*}$ & $85.9 \pm 5.0^{\mathrm{a}}$ & $163.6 \pm 31.7^{*}$ & $148.5 \pm 18.7^{*}$ & $142.8 \pm 17^{*}$ \\
\hline Triglycerides, mg/dl & $60 \pm 4^{b}$ & $67 \pm 3^{b}$ & $71 \pm 6$ & $76 \pm 4^{*}$ & $226 \pm 29^{*, a}$ & $308 \pm 69^{*}$ & $206 \pm 23^{*}$ \\
\hline $\mathrm{HDL}, \mathrm{mg} / \mathrm{dl}$ & $65 \pm 5^{\mathrm{a}, \mathrm{b}}$ & $95 \pm 6^{*, \mathrm{~b}}$ & $62 \pm 9^{a}$ & $101 \pm 3^{*}$ & $186 \pm 15^{*, a}$ & $235 \pm 24^{*, \mathrm{~b}}$ & $193 \pm 4^{*}$ \\
\hline LDL, mg/dl & $1 \pm 0^{\mathrm{b}}$ & $27 \pm 5^{\mathrm{b}}$ & n.a. & $34 \pm 8^{*}$ & $385 \pm 63^{*, a}$ & $424 \pm 28^{*}$ & $411 \pm 54^{*}$ \\
\hline
\end{tabular}

Phenotypic and metabolic parameters in WT $(\mathrm{N}=12), \mathrm{ob} / \mathrm{ob}(\mathrm{N}=11)$ and $\mathrm{DKO}(\mathrm{N}=10)$. Data for untreated groups are similar to table 1; after treatment with a hypocaloric diet in ob/ob $(\mathrm{N}=13)$ and $\mathrm{DKO}(\mathrm{N}=16)$; after treatment with $\mathrm{ACE}-\mathrm{I}$ in ob/ob $(\mathrm{N}=15)$ and DKO $(\mathrm{N}=14)$. n.a. $=$ Not available. ${ }^{*} \mathrm{p}<0.05$ vs. WT, ${ }^{\mathrm{a}} \mathrm{p}<0.05$ vs. untreated ob/ob and ${ }^{\mathrm{b}} \mathrm{p}<0.05$ vs. untreated DKO.

Vasomotor Responses of the Thoracic Aorta in vitro in WT, LDLR-/-, ob/ob and DKO at 24 Weeks

Impaired Endogenous NO-Dependent

Vasorelaxation in DKO

Figure 1a depicts a representative trace of the concentration-dependent response to ACh in WT and DKO. Figure $1 \mathrm{~b}$ demonstrates the concentration-dependent curve to ACh in preconstricted rings of WT, LDLR-/-, $\mathrm{ob} / \mathrm{ob}$ and $\mathrm{DKO}$, and figure $1 \mathrm{c}$ shows the maximum relaxation $\left(\mathrm{E}_{\max }\right)$ in the various groups. Vasorelaxation was significantly reduced in $\mathrm{ob} / \mathrm{ob}$ and $\mathrm{DKO}$, and the decrease was more pronounced in DKO.

Figure $2 \mathrm{a}$ illustrates the concentration-dependent vasorelaxant response to $\mathrm{BK}$ in preconstricted rings, and figure $2 \mathrm{~b}$ displays $\mathrm{E}_{\max }$. $\mathrm{BK}$, in contrast to $\mathrm{Ach}$, only partially relaxed the preconstricted rings. As for $\mathrm{ACh}$, vasorelaxation by BK was significantly reduced in $\mathrm{ob} / \mathrm{ob}$ and DKO mice. However, in this case, the response to BK was similarly reduced in both genotypes. In contrast to $\mathrm{ACh}$, relaxation to $\mathrm{BK}$ was increased in LDLR.

Figure $3 \mathrm{a}$ illustrates the concentration-dependent vasorelaxant response to exogenous $\mathrm{NO}$ by administration of SNP in preconstricted rings, and figure $3 \mathrm{~b}$ demonstrates $\mathrm{E}_{\max }$ in the various groups. In contrast to $\mathrm{ACh}$ and $\mathrm{BK}$, which induced a decreased vasodilatory response in $\mathrm{ob} / \mathrm{ob}$ and DKO, vasodilation after administration of SNP is comparable in all genotypes. 


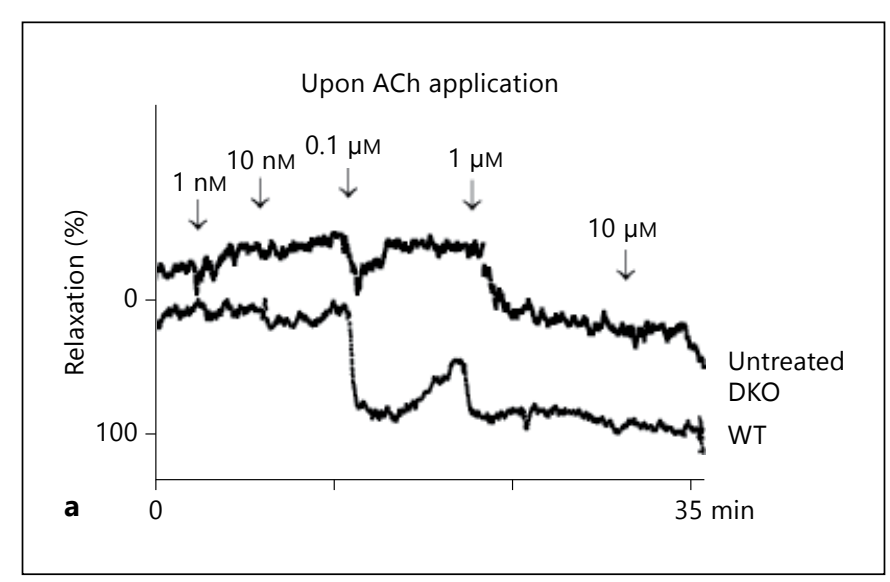

Fig. 1. Endothelium-dependent vasorelaxation in response to ACh in endothelium-intact ring segments in WT, LDLR-/-, ob/ ob and DKO at 24 weeks and effect of in vivo treatment with ACE-I or hypocaloric diet. a Representative trace of concentration-dependent response to ACh in WT and untreated DKO. Concentration-response curve $(\mathbf{b})$ and $\mathrm{E}_{\max },(\mathbf{c})$ expressed as percent relaxation, compared to the initial preconstriction with $10^{-7} \mathrm{M}$ Phe (black bars) and effect of treatment with a hypocaloric diet and ACE-I (grey bars) at 24 weeks in WT $(\mathrm{n}=14)$, LDLR-/$(\mathrm{n}=12), \mathrm{ob} / \mathrm{ob}(\mathrm{n}=13)$ and DKO $(\mathrm{n}=11) .{ }^{*} \mathrm{p}<0.05$ vs. WT, ${ }^{\mathrm{a}} \mathrm{p}<0.05$ vs. untreated ob/ob, ${ }^{\mathrm{b}} \mathrm{p}<0.05$ vs. untreated DKO, ${ }^{\mathrm{c}} \mathrm{p}<$ 0.05 vs. LDLR-/-.

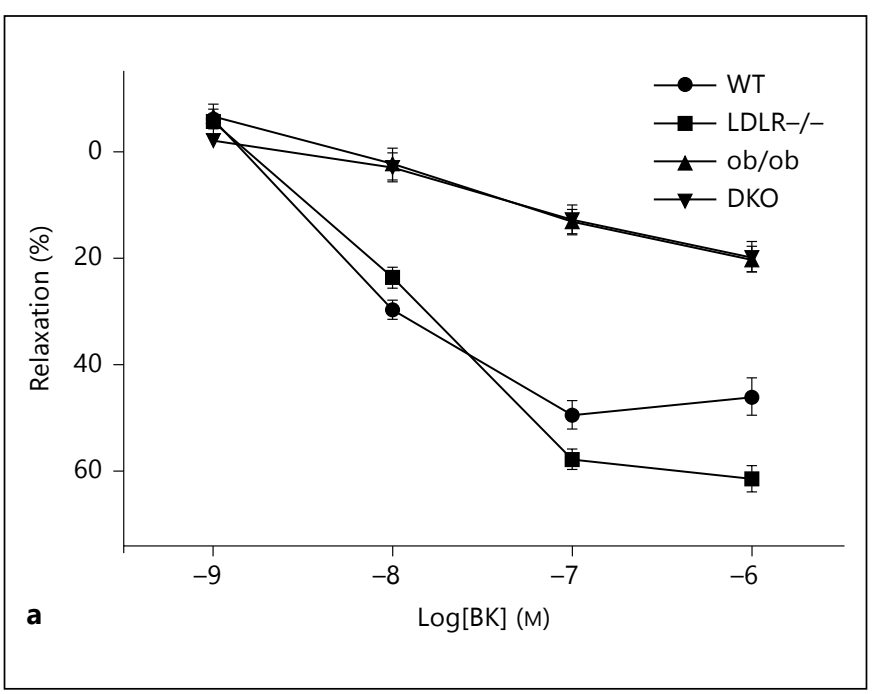

Fig. 2. Endothelium-dependent vasorelaxation in response to $B K$ in endothelium-intact ring segments in WT, LDLR-/-, ob/ob and DKO at 24 weeks and effect of in vivo treatment with ACE-I or hypocaloric diet. Concentration-response curve (a) and $\mathrm{E}_{\max }(\mathbf{b})$, expressed as percent relaxation, compared to the initial precon-
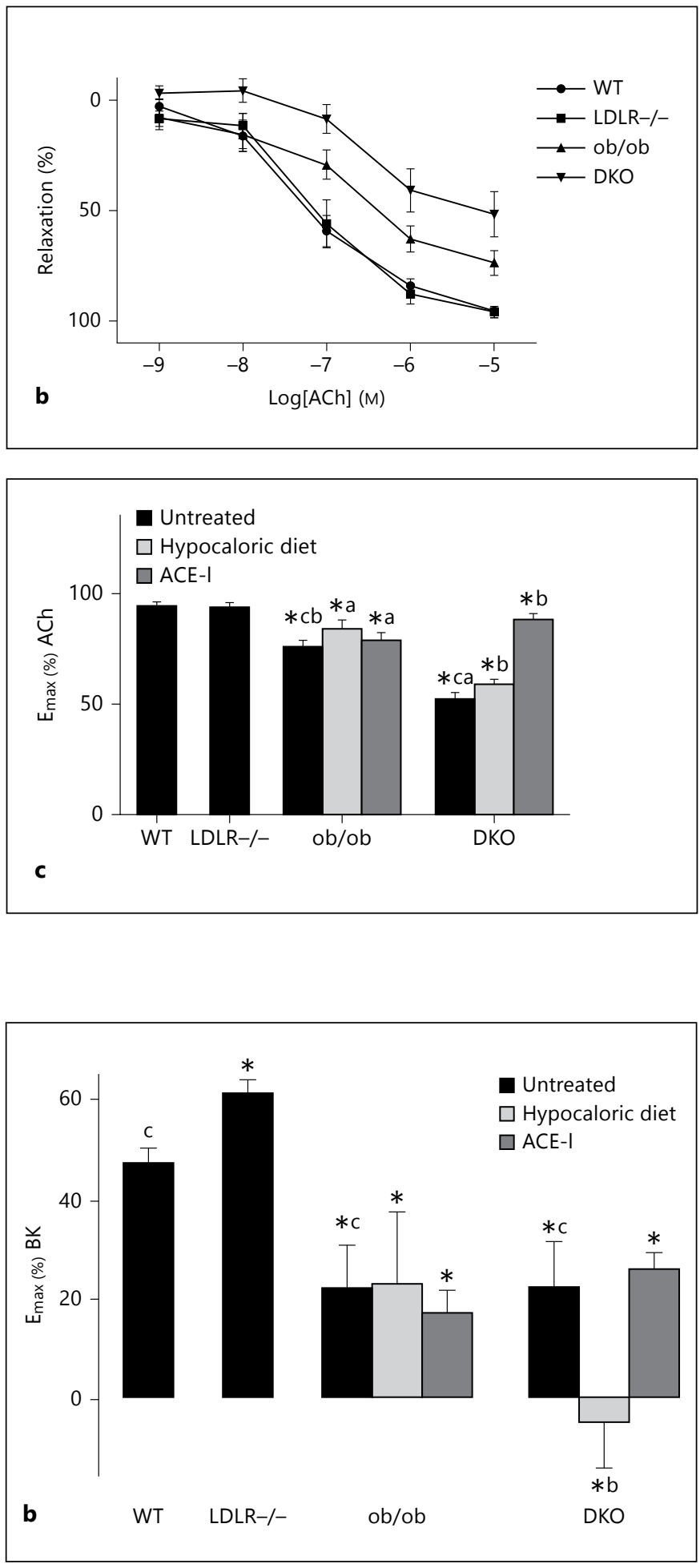

striction with $10^{-7} \mathrm{M}$ Phe (black bars) and effect of treatment with a hypocaloric diet and ACE-I (gray bars) at 24 weeks in WT ( $\mathrm{n}=$ 15), LDLR-/- $(\mathrm{n}=12), \mathrm{ob} / \mathrm{ob}(\mathrm{n}=9)$ and DKO $(\mathrm{n}=11) .{ }^{*} \mathrm{p}<0.05$ vs. WT, ${ }^{b} \mathrm{p}<0.05$ vs. untreated DKO, ${ }^{\mathrm{c}} \mathrm{p}<0.05$ vs. LDLR-/-. 


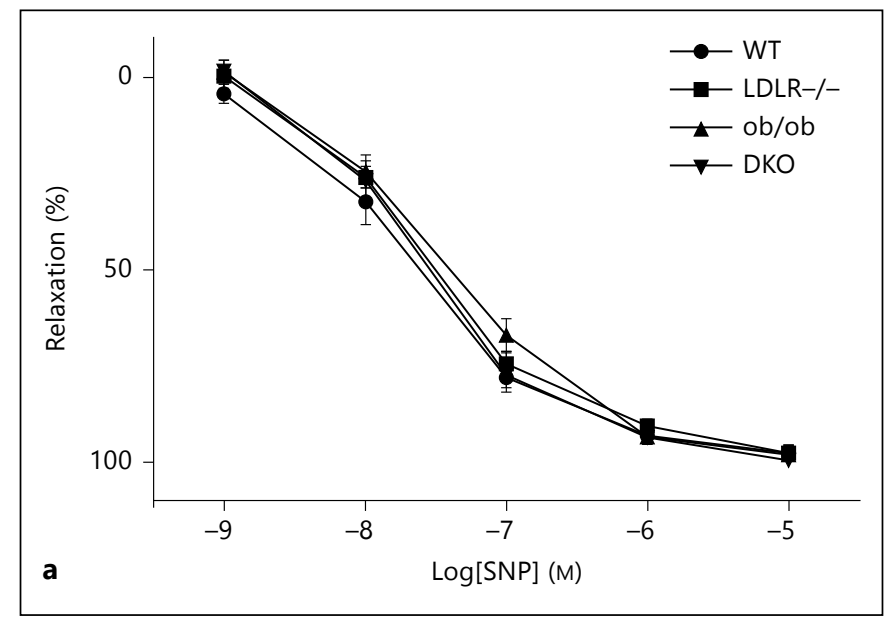

Fig. 3. Endothelium-independent vasorelaxation in response to SNP in endothelium-intact ring segments in WT, LDLR-/-, ob/ob and DKO at 24 weeks and effect of in vivo treatment with ACE-I or hypocaloric diet. Concentration-response curve (a) and $E_{\max }$ (b), expressed as percent relaxation, compared to the initial pre-

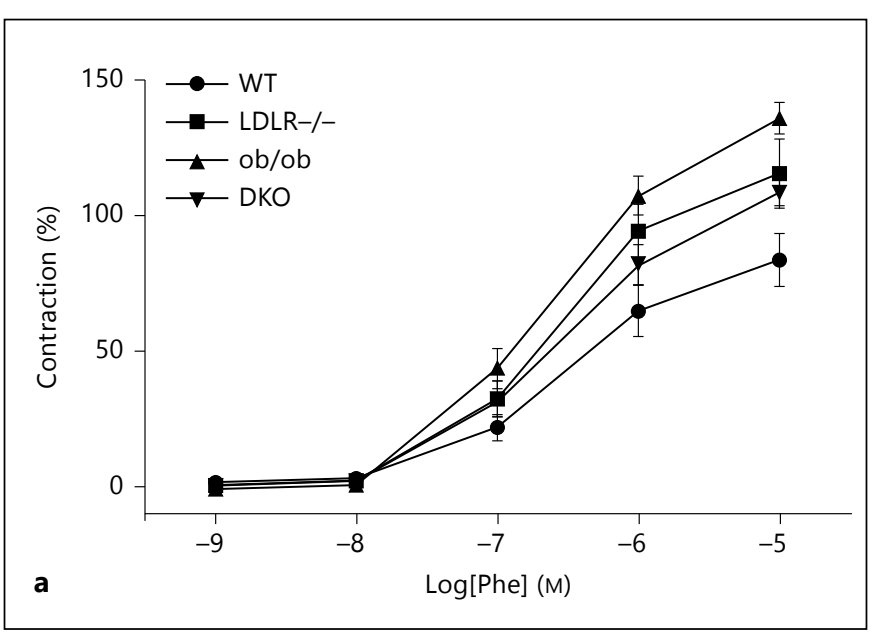

Fig. 4. Contractile response to Phe in endothelium-denuded ring segments in WT, LDLR-/-, ob/ob and DKO at 24 weeks and effect of in vivo treatment with ACE-I or a hypocaloric diet. Concentration-response curve (a) and $\mathrm{E}_{\max }(\mathbf{b})$, expressed as percent contraction, compared to $\mathrm{E}_{\max }$ of $100 \mathrm{mM} \mathrm{KCl}$ (black bars) and effect of

Augmented Contractile Response to a-Adrenergic Stimulation and Lack of Response to ATII in DKO, LDLR-/- and ob/ob

The concentration-dependent response to $\alpha$-adrenergic stimulation with Phe in endothelium-denuded ring segments is displayed in figure $4 \mathrm{a}$ and the maximum effects in figure $4 \mathrm{~b}$. The maximum effect was significantly

Vasorelaxation and the Metabolic Syndrome

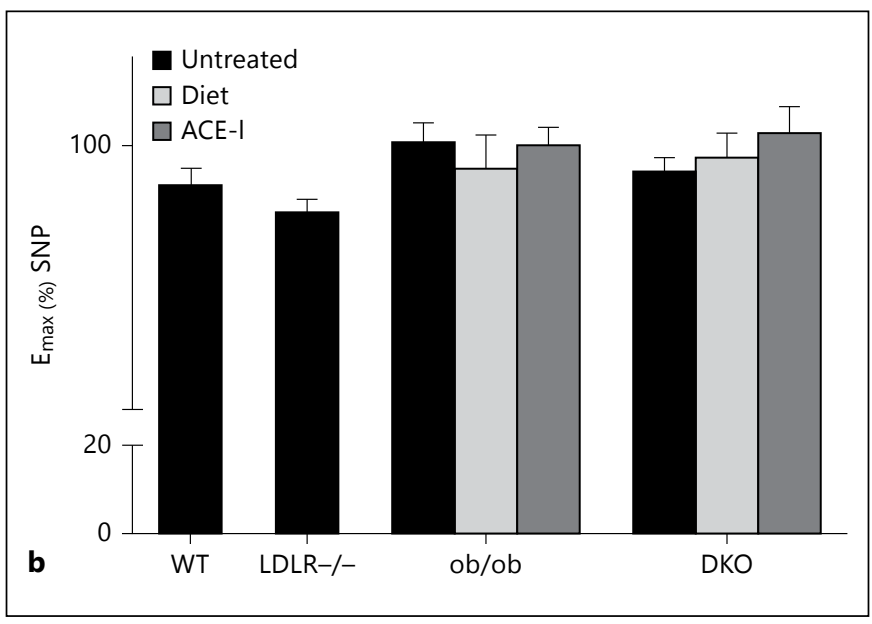

constriction with $10^{-7} \mathrm{M}$ Phe with correction for the basal vessel tonus (black bars) and effect of treatment with a hypocaloric diet and ACE-I (gray bars) at 24 weeks in WT $(\mathrm{n}=13)$, LDLR-/- $(\mathrm{n}=$ $12)$, ob/ob $(\mathrm{n}=14)$ and DKO $(\mathrm{n}=13)$.

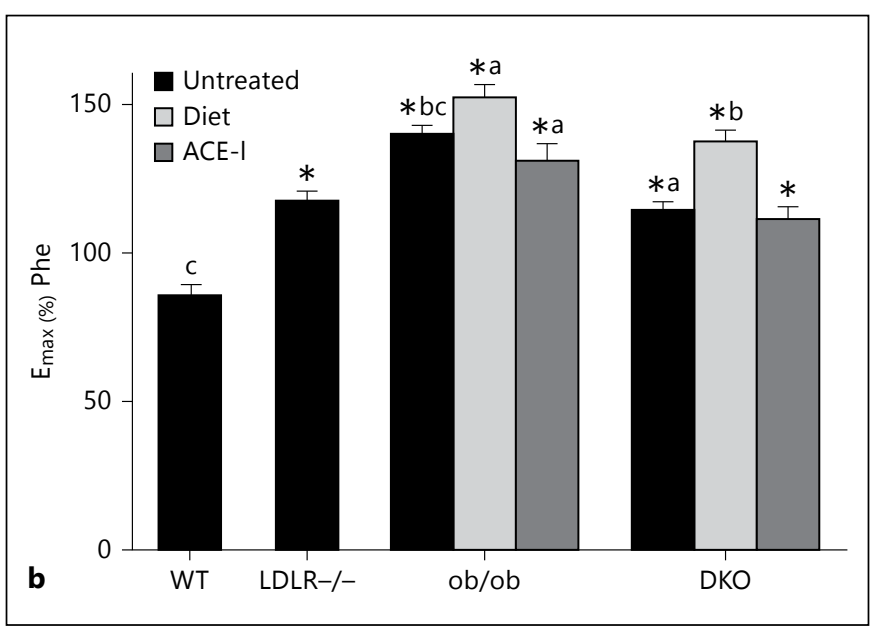

treatment with a hypocaloric diet and ACE-I (gray bars) at 24 weeks in WT $(\mathrm{n}=13)$, LDLR-/- $(\mathrm{n}=11), \mathrm{ob} / \mathrm{ob}(\mathrm{n}=12)$ and DKO $(\mathrm{n}=14) .{ }^{*} \mathrm{p}<0.05$ vs. WT, ${ }^{\mathrm{a}} \mathrm{p}<0.05$ vs. untreated ob/ob, ${ }^{\mathrm{b}} \mathrm{p}<0.05$ vs. untreated DKO, ${ }^{\mathrm{c}} \mathrm{p}<0.05$ vs. LDLR-/-.

larger in LDLR-/-, ob/ob and DKO. The response in $\mathrm{ob} / \mathrm{ob}$ even exceeded significantly that in DKO and LDLR-/-.

ATII application (in the absence of Phe) induced only a small contraction in all genotypes, varying between 3 and $5 \%$ of the response to $100 \mathrm{mM} \mathrm{KCl}$. There was no difference between the various genotypes (see online suppl. 
data; for all online suppl. material, see www.karger.com/ doi/10.1159/000355268).

The maximum contractile response to $100 \mathrm{mM} \mathrm{KCl}$ (in $\mathrm{mN} / \mathrm{mm}$ ) was not statistically different between the groups $(3.13 \pm 0.13$ in WT, $3.29 \pm 0.15$ in LDLR-/-, $2.71 \pm$ 0.14 in ob/ob and $3.03 \pm 0.14$ in DKO).

\section{Effect of a Hypocaloric Diet or ACE-I Treatment on} Vasomotor Responses in the Thoracic Aorta in vitro Improved ACh-Induced Vasorelaxation and More Enhanced $\alpha$-Adrenergic Response in DKO and ob/ob after an in vivo Hypocaloric Diet

As shown in figure 1c, 12 weeks of food restriction resulted in a small, but significant increase in $\mathrm{E}_{\max }$ in $\mathrm{DKO}$ and $\mathrm{ob} / \mathrm{ob}$. However, despite this improvement, $\mathrm{E}_{\max }$ remained significantly smaller in diet-restricted DKO and $\mathrm{ob} / \mathrm{ob}$ than in WT. Figure $2 \mathrm{~b}$ depicts that the reduced vasorelaxant response to $\mathrm{BK}$ was unchanged after treatment in ob/ob, whereas in DKO mice, all vasodilatory responses were abolished after diet. As shown in figure $3 b$, in response to SNP $E_{\max }$ is unchanged after diet compared to untreated animals.

After 12 weeks of food restriction (figure $4 \mathrm{~b}$ ), the maximum response to $a$-adrenergic stimulation was significantly increased in DKO and ob/ob compared with untreated groups.

The response to $100 \mathrm{mM} \mathrm{KCl}$ remained unchanged after diet (data not shown).

Improved Response to $\mathrm{ACh}$ in $\mathrm{DKO}$ and ob/ob after in vivo Treatment with ACE-I

As shown in figure 1c, ACE-I resulted in a significant increase in $\mathrm{E}_{\max }$ in ob/ob and $\mathrm{DKO}$, the effect being more pronounced in $\mathrm{DKO}$ mice.

The maximum vasorelaxant response to $\mathrm{BK}$ was unchanged after ACE-I (fig. 2b).

Similarly, the maximum vasorelaxant response to SNP was unchanged after ACE-I (fig. 3b).

As shown in figure $4 \mathrm{~b}$, ACE-I resulted in a small, but significant decrease in $\mathrm{E}_{\max }$ in response to Phe in ob/ob mice and unchanged maximum response in DKO mice.

The response to $\mathrm{KCl}$ is not influenced by ACE-I (data not shown).

\section{Discussion}

In this study, we determined vascular reactivity of the thoracic aorta in vitro in a mouse model of MS and compared these data with a mouse model of DMII. Secondly, the effect of in vivo treatment with ACE-I or food restriction-induced weight loss (without physical training) on vascular function was evaluated and compared in the same mouse models.

The first new finding of our study is that Ach-induced endothelium-dependent relaxation is significantly impaired in ob/ob and DKO mice, the impairment being more pronounced in the latter. The second finding is that the vasorelaxant response to $\mathrm{BK}$ is equally reduced in both genotypes. These data indicate that dyslipidemia and hypertension cause further impairment in ACh-induced relaxation in DMII mice, but not in BK-induced vasorelaxation. The third finding is that of augmented contractile responses to $\alpha$-adrenergic stimulation in $\mathrm{ob} / \mathrm{ob}$ and to a lesser extent in DKO.

The fourth finding, regarding the effect of treatment, is that ACE-I and hypocaloric diet can restore ACh-induced, but not BK-induced, vasorelaxation in both mouse models.

\section{MS Is Associated with a Larger Impairment in}

\section{Endothelium-Dependent Relaxation in Response to} ACh than DMII

ACh-induced vasodilation is mainly mediated via the endothelial subtype 3 muscarinic receptor, resulting in an increase in intracellular calcium, activation of eNOS and increased NO production [22]. NO is the major determinant of endothelium-dependent relaxation in mouse aorta under normal physiological conditions, which is in contrast to small resistance arteries where endothelial-derived hyperpolarization factor may be the main key player [3, 23]. Hyperglycemia and insulin resistance have wellknown deleterious effects on the endothelium, resulting in decreased NO bioavailability and an associated reduced response to ACh $[1,2]$. Insulin resistance alters PI3K-Akt pathway activity with a shift towards increased activity of the parallel Ras/Raf/MAP kinase pathway, leading to vascular remodeling and increased vasoconstriction [24]. Hyperglycemia, on the other hand, is associated with increased production of reactive oxygen species (ROS), which are highly active and degrade NO before it can exert its effect on VSMC $[1,2]$. Another possible contributor is leptin deficiency. Winters et al. [4] showed that endothelial dysfunction in ob/ob mice can be reversed by leptin repletion, indicating that leptin plays a role in vascular homeostasis. In addition, leptin deficiency is also known to be associated with increased oxidative stress since leptin regulates the expression of several genes involved in antioxidant defense [25]. Although both mechanisms likely contribute to the impaired response to $\mathrm{ACh}$ in $\mathrm{DKO}$, this does not provide an explanation for the difference be- 
tween DKO and ob/ob. As mentioned before, in contrast to ob/ob, atherogenic dyslipidemia and hypertension are remarkable in DKO. The harmful effects of dyslipidemia and hypertension on endothelial function are well documented. Therefore, a possible role of atherogenic dyslipidemia and/or hypertension has to be considered to explain the significant difference between ob/ob and DKO mice. Firstly, Feron et al. [26] demonstrated that LDL alters eNOS activity without changing its expression. In addition, oxidized LDL, but not native LDL, can cause inhibition of endothelium-dependent relaxation by selectively interrupting the endothelial signaling pathway [27]. In contrast, Wölfle and de Wit [23] reported that hypercholesterolemia does not severely impair vasorelaxation induced by endothelial-derived hyperpolarization factor in murine arterioles. Secondly, Puddu et al. [28] showed that endothelial function is impaired in essential hypertension, which is mainly related to decreased NO bioavailability. Taken together, these data indicate an important role for dyslipidemia and hypertension in the initiation and progression of NO-dependent endothelial dysfunction. Therefore, we hypothesize that these negative effects of dyslipidemia and hypertension might be responsible for worsening of the attenuated response to ACh in DKO compared with ob/ob. In addition, DKO mice show increased levels of oxidative stress $[18,19]$ with enhanced ROS. Accelerated inactivation of NO by ROS is associated with endothelial dysfunction [29]. This mechanism has been implicated in different pathophysiological conditions, including hypertension, hypercholesterolemia and atherosclerosis. Therefore, increased oxidative stress in DKO might also explain in part the difference between ob/ ob and DKO mice.

\section{MS Is Associated with Equal Impairment of BK-}

\section{Induced Vasorelaxation than DMII}

We show that the response to $\mathrm{BK}$ is equally reduced in $\mathrm{ob} / \mathrm{ob}$ and DKO, but significantly increased in LDLR-/-, compared with WT. The difference in response to ACh and $\mathrm{BK}$ is not surprising since $\mathrm{ACh}$ and $\mathrm{BK}$ act via different signaling pathways and suggests that dyslipidemia and/or hypertension interfere differently with these pathways. Like ACh, BK is also a potent endothelium-dependent vasodilator. BK acts via B2 receptors (B2R), which are constitutively expressed in endothelial cells with stimulation of at least 3 different parallel pathways [30] (1) activation of eNOS via phospholipase C, (2) release of endothelial-derived hyperpolarization factor (only present in small resistance arteries but not in mouse aorta $[22,23])$ and (3) stimulation of cyclo-oxygenase-2 (COX-2). The first 2 pathways are similar to those of ACh $[22,23,31]$, but stimulation of COX-2 is mainly related to BK [32]. This allows us to hypothesize that the COX-2 pathway might contribute to the divergence in endothelium-dependent vasorelaxation between ob/ob and DKO. COX-2 represents the inducible isoform of COX, which is only expressed on endothelial cells when atherosclerosis, inflammation or injury is present [33]. COX-2 catalyzes the conversion of arachidonic acid into different eicosanoids with opposing effects, e.g. prostacyclin and thromboxane. Gendron et al. [34] showed that COX-2 can preserve vasodilation in older dyslipidemic mice despite endothelial dysfunction because of a compensatory, increased production of prostacyclin when NO bioavailability is reduced. Secondly, the beneficial role of COX-2 in atherogenic conditions is supported by previous reports that selective COX-2 inhibition is associated with a significant increase in cardiovascular events in elderly patients with associated cardiovascular risk factors [35]. In addition, increased oxidative stress (as seen in DKO mice $[18,19]$ ) can also mediate COX-2 expression [36]. All together, we hypothesize that upregulation of COX-2 in response to atherogenic dyslipidemia and increased oxidative stress might play an important role in rescuing attenuated endothelium-dependent vasodilation in DKO. This concept likely provides an explanation for the two BK-related observations in our study since BK stimulates COX-2 activity. First, increased prostacyclin production via upregulation of COX-2 might prevent worsening of attenuated vasodilation in $\mathrm{DKO}$, which was confirmed by an equally impaired response to $\mathrm{BK}$ in ob/ob and $\mathrm{DKO}$ in contrast to significantly impaired responses to ACh in DKO. Secondly, the responses of LDLR-/- mice to ACh were comparable to those of WT, but a significantly better relaxation to $\mathrm{BK}$, which might be explained by upregulation of COX-2 and increased production of prostacyclin in response to the atherogenic dyslipidemia present in this mouse model. Further experiments with specific endothelial COX-2 inhibitors would be useful to gain a deeper insight into this mechanism.

\section{Enhanced $\alpha$-Adrenergic Responsiveness and Lack of Response to ATII in DKO and ob/ob}

As shown in previous studies, enhanced contractile response to $\alpha$-adrenergic stimulation by $\mathrm{Phe}$ in ob/ob was also present in our study [3]. DKO show also $\alpha$-adrenergic contractile hyperreactivity, although to a lesser extent. These alterations were specific for the $\alpha$-adrenoceptor agonist, since responses to $\mathrm{KCl}$-induced depolarization were unaltered and not due to a decreased constitutive activity of eNOS in dyslipidemic mice since the endothe- 
lium-denuded segments were studied [37]. It has been shown that COX-2 is upregulated in aortic VSMC in $\mathrm{db} / \mathrm{db}$ mice, which contributes to VSMC contractile hyperreactivity [38]. Several other participating mechanisms have been proposed: alterations in calcium handling in VSMC, enhanced calcium sensitization of myofilaments, altered $\alpha$-adrenoreceptor expression/activity and changes in distal signaling pathways $[3,6,38,39]$. However, the exact pathophysiological mechanisms underlying the differences between ob/ob and DKO mice still need to be explored. Atherogenic dyslipidemia and/ or hypertension are likely to be again the key players, but this requires further investigation.

\section{Effect of ACE-I on Vasomotor Responses of the}

Thoracic Aorta in vitro

ACE catalyzes the conversion of ATI into ATII, with simultaneous degradation of BK in inactive peptides. Enhanced production of angiotensinogen and ACE activity results in increased levels of ATII and decreased BK concentrations in case of DMII or obesity [40-42]. Most known detrimental effects of ATII are mediated via AT1 receptors (AT1R) and can be opposed by ATII-induced activation of AT2 receptors or by binding of BK to B2R. AT1R expression is upregulated in case of hyperglycemia and increased levels of circulating LDL [43-45]. Activation of AT1R leads to increased ROS production, which is mediated via NADPH oxidase, and uncoupling of eNOS and mitochondrial oxidation [44, 46, 47]. Crosstalk between these sources of ROS has been demonstrated, resulting in an ROS-dependent self-propagation [46]. ACE-I was shown to recouple eNOS, to normalize insulin signaling and to reduce oxidative stress, leading to improved endothelial function because of increased $\mathrm{NO}$ bioavailability [10, 13, 46, 48]. These mechanisms likely contribute to improved ACh-induced vasorelaxation in our mice, and this effect was more pronounced in DKO than ob/ob. Therefore, DKO might have more benefit of treatment with ACE-I than ob/ob possibly due to additional effects of ACE-I on hypertension and dyslipidemia in DKO. ACE-I reduces blood pressure in patients with hypertension and diabetes $[49,50]$, which leads to changes in shear stress, favoring vasodilation. Secondly, ACE-I reduces LDL peroxidation in hypertensive patients as well as in atherosclerotic mice [51], which results in reduced circulating oxidized LDL with less endothelial injury. However, as shown by Pollare et al. [52] and confirmed in the present study, captopril has no or little effect on serum lipid or lipoprotein levels. Therefore, additional treatment with lipid-lowering statins is ex- pected to be useful in patients with MS to reduce levels of circulating cholesterol, in particular LDL, since native LDL is known to upregulate AT1R in rat thoracic aorta VSMC [45]. In addition, native LDL causes elevation in intracellular calcium concentration and induces vasoconstriction of rat aortic rings $[53,54]$.

In contrast, ACE-I did not improve the vasorelaxant response to exogenous $\mathrm{BK}$. This result might be rather unexpected, but is concordant with previous clinical studies. Mancini et al. [55] concluded that prolongation of the half-life of BK by ACE-I is probably not the mechanism underlying the beneficial effect of ACE-I in patients with coronary artery disease. Secondly, ACE-I might potentiate the effect of BK on fibrinolytic function more than favoring its vasodilatory properties. This implies that the BK-mediated beneficial effect of ACE-I possibly relies more on pathways other than improved vasodilation [56]. This hypothesis is supported by Brown et al. [57], who showed that ACE-I increases prostacyclin production via BK in hypertensive patients, but simultaneously attenuates this effect via a BK-independent pathway. Another important consideration is that plasma metabolism of $\mathrm{BK}$ is not exclusively related to ACE. A second pathway is the conversion of BK into des-Arg-BK (DABK) by kininase I, representing a minor metabolic pathway in normal physiological conditions. This pathway is upregulated when ACE is inhibited, resulting in increased serum levels of DABK [58]. This is a selective BK B1 receptor (B1R) agonist whereas $\mathrm{BK}$ cannot bind to B1R. B1R are induced when inflammation or atherosclerosis is present. It can be assumed that part of the beneficial effect of increased endogenous $\mathrm{BK}$ is related to increased conversion of BK into DABK. Taken together, these data can provide an explanation for our results in vitro: (1) ACE-I might potentiate other beneficial effects of BK more than its vasodilatory properties to contribute to reduced vascular complications and (2) exogenous BK can improve endothelial function in vivo, but not in vitro, probably due to insufficient possibility to metabolize BK into DABK.

Our data thus show that ACE-I can restore ACh-induced vasorelaxation, which is solely NO dependent in mouse thoracic aorta. In contrast, ACE-I is unable to correct impaired BK-dependent vasorelaxation, probably largely mediated via endothelial COX-2. Therefore, we hypothesize that ACE-I can restore NO-dependent endothelial-mediated vasorelaxation, but not endothelial COX2-mediated vasorelaxation. This hypothesis is supported by a study by Tiefenbacher et al. [59] showing that lisinopril significantly improves impaired NO-dependent vasorelaxation in atherosclerotic human coronary arterioles. 


\section{Effect of Hypocaloric Diet-Induced Weight Loss on}

Vasomotor Responses

DMII is often associated with obesity, an additional and independent risk factor for cardiovascular disease. Therefore, weight loss is considered to be essential in the treatment of obese patients with DMII. Short-term, very-low-caloric diet, as well as long-term weight loss $>10 \%$ ameliorates endothelial function in obese women $[14,15]$. In contrast, Bergholm et al. [60] reported that improved endothelial function might be rather explained by decreased LDL levels than weight loss. Most studies on food restriction in obese patients with DMII are associated with exercise training. Increased physical activity restores endothelial function in DMII $[16,17]$ independently of weight loss or glycemia [61]. We showed that food restriction-induced weight loss without exercise training can improve ACh-induced vasorelaxation, but not the attenuated response to $\mathrm{BK}$ in ob/ob and DKO. Additionally, weight loss resulted in further enhancement of $\alpha$-adrenergic responsiveness in both genotypes. These opposing findings might be explained by the extreme weight loss that our mice experienced because extreme weight loss results in starvation, which is associated with increased cardiovascular complications [62].

\section{Limitations of our Study}

A limitation of our study is the leptin deficiency in our mouse model. In humans, uncorrected obesity is associated with increased plasma levels of leptin. Long-term hyperleptinemia results in leptin resistance. Leptin resistance and interrupted leptin signaling were reported under hyperleptinemic conditions [63], making hyperleptinemia essentially comparable to leptin deficiency regarding the signaling pathways of leptin.

Another limitation of our study is the fact that our study is only performed in isolated aortic ring segments but not in (small) resistance vessels.

In the present study, we did not combine ACE-I with a hypocaloric diet. It can be assumed that the combination of both would maximize the beneficial vascular effects in DMII and MS. This needs to be elucidated in the future, as well as the potential role of the COX-2 pathway (by using a selective COX-2 inhibitor or determining gene or protein expression of COX-2).

\section{Conclusion}

Our data indicate a differential impact of DMII and MS on endothelial function. ACE-I and hypocaloric diet improved ACh-, but not BK-induced vasorelaxation in these mouse models of DMII and MS.

\section{Acknowledgments}

This study was supported by a PhD fellowship of the Research Foundation-Flanders (FWO) to Ines Nevelsteen and by a grant of the Research Fund KU Leuven-Bijzonder Onderzoeksfonds (OT 04/39, OT 05/55 and PF/10/014).

\section{References}

-1 De Vriese AS, Verbeuren TJ, Van de Voorde J, Lameire NH, Vanhoutte PM: Endothelial dysfunction in diabetes. Br J Pharmacol 2000; 130:963-974.

-2 Schalkwijk CG, Stehouwer CD: Vascular complications in diabetes mellitus: the role of endothelial dysfunction. Clin Sci (Lond) 2005; 109:143-159.

-3 Okon EB, Szado T, Laher I, McManus B, van Breemen C: Augmented contractile response of vascular smooth muscle in a diabetic mouse model. J Vasc Res 2003;40:520-530.

$\checkmark 4$ Winters B, Mo Z, Brooks-Asplund E, Kim S, Shoukas A, Li D, Nyhan D, Berkowitz DE: Reduction of obesity, as induced by leptin, reverses endothelial dysfunction in obese (Lep(ob)) mice. J Appl Physiol 2000;89:2382-2390.

-5 Miike T, Kunishiro K, Kanda M, Azukizawa S, Kurahashi K, Shirahase H: Impairment of endothelium-dependent ACh-induced relaxation in aorta of diabetic $\mathrm{db} / \mathrm{db}$ mice - possi- ble dysfunction of receptor and/or receptor-G protein coupling. Naunyn Schmiedebergs Arch Pharmacol 2008;377:401-410.

6 Balasubramanyam M, Balaji RA, Subashini B, Mohan V: Evidence for mechanistic alterations of $\mathrm{Ca}^{2+}$ homeostasis in type 2 diabetes mellitus. Int J Exp Diabetes Res 2001;1:275-287.

7 Levy J, Gavin JR 3rd, Sowers JR: Diabetes mellitus: a disease of abnormal cellular calcium metabolism? Am J Med 1994;96:260-273.

-8 Grundy SM, Brewer HB Jr, Cleeman JI, Smith SC Jr, Lenfant C: Definition of metabolic syndrome: report of the National Heart, Lung, and Blood Institute/American Heart Association conference on scientific issues related to definition. Circulation 2004;109:433-438.

-9 Van den Bergh A, Vanderper A, Vangheluwe P, Desjardins F, Nevelsteen I, Verreth W, Wuytack F, Holvoet P, Flameng W, Balligand JL, Herijgers P: Dyslipidaemia in type II diabetic mice does not aggravate contractile im- pairment but increases ventricular stiffness. Cardiovasc Res 2008;77:371-379.

10 Fiordaliso F, Cuccovillo I, Bianchi R, Bai A, Doni M, Salio M, De Angelis N, Ghezzi P, Latini R, Masson S: Cardiovascular oxidative stress is reduced by an ACE inhibitor in a rat model of streptozotocin-induced diabetes. Life Sci 2006;79:121-129.

$\$ 11$ Keidar S, Attias J, Coleman R, Wirth K, Schölkens B, Hayek T: Attenuation of atherosclerosis in apolipoprotein E-deficient mice by ramipril is dissociated from its antihypertensive effect and from potentiation of bradykinin. J Cardiovasc Pharmacol 2000;35:64-72.

12 Buikema H, Monnink SH, Tio RA, Crijns HJ, de Zeeuw D, van Gilst WH: Comparison of zofenopril and lisinopril to study the role of the sulfhydryl-group in improvement of endothelial dysfunction with ACE-inhibitors in experimental heart failure. Br J Pharmacol 2000;130:1999-2007.
Vasorelaxation and the Metabolic Syndrome
J Vasc Res 2013;50:486-497 DOI: $10.1159 / 000355221$ 
13 Khan BV, Sola S, Lauten WB, Natarajan R, Hooper WC, Menon RG, Lerakis S, Helmy T: Quinapril, an ACE inhibitor, reduces markers of oxidative stress in the metabolic syndrome. Diabetes Care 2004;27:1712-1715.

14 Sasaki S, Higashi Y, Nakagawa K, Kimura M, Noma K, Sasaki S, Hara K, Matsuura H, Goto C, Oshima T, Chayama K: A low-calorie diet improves endothelium-dependent vasodilation in obese patients with essential hypertension. Am J Hypertens 2002;15:302-309.

-15 Ziccardi P, Nappo F, Giugliano G, Esposito K, Marfella R, Cioffi M, D’Andrea F, Molinari AM, Giugliano D: Reduction of inflammatory cytokine concentrations and improvement of endothelial functions in obese women after weight loss over one year. Circulation 2002; 105:804-809.

16 Lee S, Park Y, Zhang C: Exercise training prevents coronary endothelial dysfunction in type 2 diabetic mice. Am J Biomed Sci 2011;3: 241-252.

17 Lee S, Park Y, Dellsperger KC, Zhang C: Exercise training improves endothelial function via adiponectin-dependent and independent pathways in type 2 diabetic mice. Am J Physiol Heart Circ Physiol 2011; 301:H306-H314.

-18 Mertens A, Verhamme P, Bielicki JK, Phillips MC, Quarck R, Verreth W, Stengel D, Ninio E, Navab M, Mackness B, Mackness M, Holvoet $\mathrm{P}$ : Increased low-density lipoprotein oxidation and impaired high-density lipoprotein antioxidant defense are associated with increased macrophage homing and atherosclerosis in dyslipidemic obese mice: LCAT gene transfer decreases atherosclerosis. Circulation 2003;107:1640-1646.

19 Verreth W, De Keyzer D, Pelat M, Verhamme P, Ganame J, Bielicki JK, Mertens A, Quarck R, Benhabilès N, Marguerie G, Mackness B, Mackness M, Ninio E, Herregods MC, Balligand JL, Holvoet P: Weight-loss-associated induction of peroxisome proliferator-activated receptor-alpha and peroxisome proliferator-activated receptor-gamma correlate with reduced atherosclerosis and improved cardiovascular function in obese insulin-resistant mice. Circulation 2004;110:3259-3269.

$\checkmark 20$ Wichi RB, Farah V, Chen Y, Irigoyen MC, Morris M: Deficiency in angiotensin AT1a receptors prevents diabetes-induced hypertension. Am J Physiol Regul Integr Comp Physiol 2007;292:R1184-R1189.

-21 Van Hove CE, Van der Donckt C, Herman AG, Bult H, Fransen P: Vasodilator efficacy of nitric oxide depends on mechanisms of intracellular calcium mobilization in mouse aortic smooth muscle cells. Br J Pharmacol 2009; 158:920-930.

22 Huang PL, Huang Z, Mashimo H, Bloch KD, Moskowitz MA, Bevan JA, Fishman MC: Hypertension in mice lacking the gene for endothelial nitric oxide synthase. Nature 1995;377: 239-242.

23 Wölfle SE, de Wit C: Intact endothelium-dependent dilation and conducted responses in resistance vessels of hypercholesterolemic mice in vivo. J Vasc Res 2005;42:475-482.

24 Kim JA, Montagnani M, Koh KK, Quon MJ: Reciprocal relationships between insulin resistance and endothelial dysfunction: molecular and pathophysiological mechanisms. Circulation 2006;113:1888-1904.

25 Liang CP, Tall AR: Transcriptional profiling reveals global defects in energy metabolism, lipoprotein, and bile acid synthesis and transport with reversal by leptin treatment in ob/ob mouse liver. J Biol Chem 2001;276:4906649076.

26 Feron O, Dessy C, Desager JP, Balligand JL: Hydroxy-methylglutaryl-coenzyme A reductase inhibition promotes endothelial nitric oxide synthase activation through a decrease in caveolin abundance. Circulation 2001;103: $113-118$.

27 Kugiyama K, Kerns SA, Morrisett JD, Roberts R, Henry PD: Impairment of endotheliumdependent arterial relaxation by lysolecithin in modified low-density lipoproteins. Nature 1990;344:160-162.

28 Puddu P, Puddu GM, Zaca F, Muscari A: Endothelial dysfunction in hypertension (review). Acta Cardiol 2000;55:221-232.

29 Cai H, Harrison DG: Endothelial dysfunction in cardiovascular diseases: the role of oxidant stress. Circ Res 2000;87:840-844.

30 Heitsch H: Bradykinin B2 receptor as a potential therapeutic target. Drug News Perspect 2000;13:213-225.

31 Chlopicki S, Kozlovski VI, Lorkowska B, Drelicharz L, Gebska A: Compensation of endothelium-dependent responses in coronary circulation of eNOS-deficient mice. J Cardiovasc Pharmacol 2005;46:115-123.

32 Rodriguez JA, De la Cerda P, Collyer E, Decap V, Vio CP, Velarde V: Cyclooxygenase-2 induction by bradykinin in aortic vascular smooth muscle cells. Am J Physiol Heart Circ Physiol 2006;290:H30-H36.

33 Schönbeck U, Sukhova GK, Graber P, Coulter S, Libby P: Augmented expression of cyclooxygenase-2 in human atherosclerotic lesions. Am J Pathol 1999;155:1281-1291.

-34 Gendron ME, Thorin-Trescases N, Villeneuve L, Thorin E: Aging associated with mild dyslipidemia reveals that COX-2 preserves dilation despite endothelial dysfunction. Am J Physiol Heart Circ Physiol 2007;292:H451-H458.

35 Mukherjee D, Nissen SE, Topol EJ: Risk of cardiovascular events associated with selective COX-2 inhibitors. JAMA 2001;286:954-959.

36 Feng L, Xia Y, Garcia GE, Hwang D, Wilson $\mathrm{CB}$ : Involvement of reactive oxygen intermediates in cyclooxygenase-2 expression induced by interleukin-1, tumor necrosis factor-alpha, and lipopolysaccharide. J Clin Invest 1995;95:1669-1675.

37 Fransen P, Van Assche T, Guns PJ, Van Hove CE, De Keulenaer GW, Herman AG, Bult H: Endothelial function in aorta segments of apolipoprotein E-deficient mice before development of atherosclerotic lesions. Pflügers Arch 2008;455:811-818.
38 Guo Z, Su W, Allen S, Pang H, Daugherty A, Smart E, Gong MC: COX-2 up-regulation and vascular smooth muscle contractile hyperreactivity in spontaneous diabetic $\mathrm{db} / \mathrm{db}$ mice. Cardiovasc Res 2005;67:723-735.

39 Liu Y, Gutterman DD: The coronary circulation in diabetes: influence of reactive oxygen species on $\mathrm{K}+$ channel-mediated vasodilation. Vascul Pharmacol 2002;38:43-49.

40 Phillips MI, Speakman EA, Kimura B: Levels of angiotensin and molecular biology of the tissue renin angiotensin systems. Regul Pept 1993;43:1-20.

41 Frederich RC Jr, Kahn BB, Peach MJ, Flier JS: Tissue-specific nutritional regulation of angiotensinogen in adipose tissue. Hypertension 1992;19:339-344.

42 Tesfamariam B, Cohen RA: Free radicals mediate endothelial cell dysfunction caused by elevated glucose. Am J Physiol 1992;263: H321-H326.

43 Sodhi CP, Kanwar YS, Sahai A: Hypoxia and high glucose upregulate AT1 receptor expression and potentiate ANG II-induced proliferation in VSM cells. Am J Physiol Heart Circ Physiol 2003;284:H846-H852.

44 Wong WT, Tian XY, Xu A, Ng CF, Lee HK, Chen ZY, Au CL, Yao X, Huang Y: Angiotensin II type 1 receptor-dependent oxidative stress mediates endothelial dysfunction in type 2 diabetic mice. Antioxid Redox Signal 2010;13:757-768.

-45 Nickenig G, Sachinidis A, Seewald S, Böhm $\mathrm{M}$, Vetter H: Influence of oxidized low-density lipoprotein on vascular angiotensin II receptor expression. J Hypertens Suppl 1997; 15:S27-S30.

$46 \mathrm{Oak} \mathrm{JH}$, Cai H: Attenuation of angiotensin II signaling recouples eNOS and inhibits nonendothelial NOX activity in diabetic mice. Diabetes 2007;56:118-126.

47 Taguchi K, Kobayashi T, Takenouchi Y, Matsumoto T, Kamata K: Angiotensin II causes endothelial dysfunction via the GRK2/Akt/ eNOS pathway in aortas from a murine type 2 diabetic model. Pharmacol Res 2011;64: 535-546.

48 Tabbi-Anneni I, Buchanan J, Cooksey RC, Abel ED: Captopril normalizes insulin signaling and insulin-regulated substrate metabolism in obese (ob/ob) mouse hearts. Endocrinology 2008;149:4043-4050.

49 Robertson JI, Tillman DM: Converting enzyme inhibitors in the treatment of hypertension. J Cardiovasc Pharmacol 1987;10(suppl 7):S43-S48.

50 Buse JB, Ginsberg HN, Bakris GL, Clark NG, Costa F, Eckel R, Fonseca V, Gerstein HC, Grundy S, Nesto RW, Pignone MP, Plutzky J, Porte D, Redberg R, Stitzel KF, Stone NJ, American Heart Association, American Diabetes Association: Primary prevention of cardiovascular disease in people with diabetes mellitus. A scientific statement from the American Heart Association and the American Diabetes Association. Circulation 2007;115: 114-126. 
51 Keidar S: Angiotensin, LDL peroxidation and atherosclerosis. Life Sci 1998;63:1-11.

52 Pollare T, Lithell H, Berne C: A comparison of the effects of hydrochlorothiazide and captopril on glucose and lipid metabolism in patients with hypertension. N Engl J Med 1989; 321:868-873.

53 Sachinidis A, Locher R, Vetter W: Generation of intracellular signals by low density lipoprotein is independent of the classical LDL receptor. Am J Hypertens 1991;4:274-279.

54 Sachinidis A, Mendgen T, Locher R, Brunner C, Vetter W: Novel activities for low density lipoprotein in vascular smooth muscle cells. Hypertension 1990;15:704-711.

55 Mancini GB, Henry GC, Macaya C, O’Neill BJ, Pucillo AL, Carere RG, Wargovich TJ, Mudra H, Lüscher TF, Klibaner MI, Haber HE, Uprichard AC, Pepine CJ, Pitt B: Angiotensin-converting enzyme inhibition with quinapril improves endothelial vasomotor dysfunction in patients with coronary artery disease. The TREND (Trial on Reversing ENdothelial Dysfunction) Study. Circulation 1996;94:258-265, erratum p 1490.
56 Pretorius M, Rosenbaum D, Vaughan DE, Brown NJ: Angiotensin-converting enzyme inhibition increases human vascular tissuetype plasminogen activator release through endogenous bradykinin. Circulation 2003; 107:579-585.

57 Brown NJ, Ryder D, Gainer JV, Morrow JD, Nadeau J: Differential effects of angiotensin converting enzyme inhibitors on the vasodepressor and prostacyclin responses to bradykinin. J Pharmacol Exp Ther 1996;279:703712.

8 Décarie A, Raymond P, Gervais N, Couture R, Adam A: Serum interspecies differences in metabolic pathways of bradykinin and [desArg9]BK: influence of enalaprilat. Am J Physiol 1996;271:H1340-H1347.
59 Tiefenbacher CP, Friedrich S, Bleeke T, Vahl C, Chen X, Niroomand F: ACE inhibitors and statins acutely improve endothelial dysfunction of human coronary arterioles. Am J Physiol Heart Circ Physiol 2004;286:H1425-H1432.

60 Bergholm R, Tiikkainen M, Vehkavaara S, Tamminen M, Teramo K, Rissanen A, YkiJärvinen $\mathrm{H}$ : Lowering of LDL cholesterol rather than moderate weight loss improves endothelium-dependent vasodilatation in obese women with previous gestational diabetes. Diabetes Care 2003;26:1667-1672.

61 Moien-Afshari F, Ghosh S, Elmi S, Rahman MM, Sallam N, Khazaei M, Kieffer TJ, Brownsey RW, Laher I: Exercise restores endothelial function independently of weight loss or hyperglycaemic status in $\mathrm{db} / \mathrm{db}$ mice. Diabetologia 2008;51:1327-1337, erratum 2009;52:181.

62 Poirier P, Eckel RH: Obesity and cardiovascular disease. Curr Atheroscler Rep 2002;4:448453.

$\checkmark 63$ Ren J: Leptin and hyperleptinemia - from friend to foe for cardiovascular function. J Endocrinol 2004;181:1-10. 